See discussions, stats, and author profiles for this publication at: https://www.researchgate.net/publication/250010178

\title{
Evaluation of wheat germplasm from the Madeira and Canary archipelagos using a single molecular marker. A rapid screening method for identification of durum wheat accessions
}

Article in Cereal Research Communications · September 2007

DOI: $10.1556 / C R C .35 .2007 .3 .4$

CITATIONS

4

5 authors, including:

Teresa Santos

ISOPlexis gene bank

22 PUBLICATIONS 392 CITATIONS

SEE PROFILE

Graça Costa

Universidade da Madeira

45 PUBlicATIONS 726 CITATIONS

SEE PROFILE
READS

51

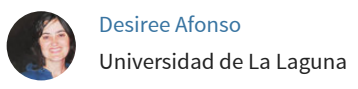

20 PUBLICATIONS 93 CITATIONS

SEE PROFILE

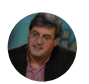

Miguel Â. Almeida Pinheiro de Carvalho

Universidade da Madeira

130 PUBLICATIONS 957 CITATIONS

SEE PROFILE

Some of the authors of this publication are also working on these related projects:

Recuperación de cereales de invierno en la isla de Tenerife View project

Legumes y mesturas. Caracterización de leguminosas forrajeras de secano vernáculas de la cumbre de Gran Canaria View project 


\title{
Evaluation of Wheat Germplasm from the Madeira and Canary Archipelagos Using a Single Molecular Marker. A Rapid Screening Method for Identification of Durum Wheat Accessions
}

\author{
V. AndRAdE ${ }^{1}$, T.M.M. DOS SANTOS ${ }^{1}$, D. AfOnSO MORAlES ${ }^{2}$, G. COSTA $^{1}$ \\ and M.A.A. PINHEIRO DE CARVALHO ${ }^{1 *}$ \\ ${ }^{1}$ ISOPlexis/BIOtecMOL, Centre of Macaronesian Studies, University of Madeira, \\ Campus da Penteada, 9000-390 Funchal, Portugal \\ ${ }^{2}$ Centro de Conservación de la Biodiversidad Agrícola de Tenerife, \\ Tacaronte, Tenerife, Spain
}

(Received 12 October 2006; accepted 20 March 2007)

\begin{abstract}
This work aims to present a rapid and precise screening method of wheat germplasm and identification of durum wheat accessions in germplasm collections. Fifty-two wheat accessions maintained in the ISOPlexis germplasm bank at the Madeira University, Portugal, and 72 accessions from the Centre for Conservation of Crop Biodiversity of Tenerife (CCBAT), Spain, have been screened for their specific ploidy status using the molecular marker Dgas44. We have demonstrated that the Dgas44 sequence is effective in the screening of Madeiran and Canarian wheat accessions. This screening method permitted the detection of 10 and 11 durum accessions among Madeiran and Canarian wheats, accounting for 19.2 and $15.3 \%$ of screened collections, respectively. The obtained results have shown a $100 \%$ of cases correspondence with the previously performed morphological identification of the Madeiran wheats. It also permitted rectification and clarification of previous classification of some accessions based only on the morphological traits. The PCR based assay was directly applicable to the screening of seeds and was suitable for detecting seed mixtures in accessions. This rapid method has been proven to be a useful tool in gene bank accessions management including verification of their ploidy status and detection of seed lots adulteration.
\end{abstract}

Keywords: durum wheat, germplasm, D genome, DNA, PCR, Dgas44

\section{Introduction}

The current wheat genetic diversity on the Archipelago of Madeira is the result of several germplasm introductions from various geographical locations (Vieira 1983). These introductions, as well as cultivar adaptation to local conditions, tra-

\footnotetext{
*Corresponding author; E-mail: quercus@uma.pt; Fax: +351 291705399
} 
ditional agricultural practices and the artificial selection performed by farmers, have determined the evolution of a crop diversity possessing unique morphological and agronomic features (Pinheiro de Carvalho et al. 2003). Wheat diversity of the Madeira and Canary archipelagos has been monitored, and its phytogenetic resources conserved as germplasm collections in the ISOPlexis germplasm Bank, at the University of Madeira and in the Centre for Conservation of Crop Biodiversity of Tenerife (CCBAT). The ISOPlexis and CCBAT banks make an effort to preserve traditional wheat landraces on both archipelagos, through an extensive program of diversity monitoring and germplasm management. The characterization and identification of germplasm accessions are primarily done based on morphological and physiological traits. These morphological and physiological descriptors are useful but may be affected by environmental factors and their analysis is time consuming.

For such reason, the use of molecular markers as a fast technique for fingerprinting and screening of varieties or accessions with agricultural relevance have recently received researcher's attention. Molecular markers can complement morphological characterization because they are plentiful and independent of tissue or environmental effects (Manifesto et al. 2001; Perry 2004). The accessions characterization aims to promote the crop varieties description, seed certification and, probably the most important, their germplasm protection (Dograr et al. 2000). It is also necessary to assess the distinctness, uniformity and stability of new cultivars for certification (Pasqualone et al. 1999). To keep the accessions value unchanged in a germplasm bank, seed contaminations or mixture must be eliminated. At the same time, additional attention needs to be paid to avoid the genetic erosion phenomena of germplasm collections. Usually, to prevent these phenomena samples need to be periodically in situ collected or regenerated, which could lead to the adulteration of the accessions. To avoid the possibility of seed mixture and accidental contaminations occurring during either wheat harvest or storage routine quality control, tests for screening of accessions are essential. PCR based markers that require very small amounts of DNA seem to be a relatively rapid tool for germplasm screening. Bryan et al. (1998) have reported a PCR method based upon a D genome amplified sequence, which can be used to detect the presence of the wheat $\mathrm{D}$ genome and distinguish tetraploid from hexaploid accessions. The screening of the wheat species in germplasm collection using molecular markers facilitate further morphological characterization and can act as a substitute for cariotype analysis as it is faster and more reliable.

In this work, we present the results of screening for the presence of $\mathrm{D}$ genome in 52 and 72 wheat accessions from the Madeira and Canary Archipelagos, re- 
spectively. The aim of this work is to establish a rapid and accurate screening method for wheat accessions using a single molecular marker.

\section{Materials and Methods}

\section{Seed material}

Fifty-two and seventy-two accessions conserved in the ISOPlexis and CCTAB collections were used as representatives of wheat diversity from the Madeira and Canary Islands (Tables 1 and 2). Avonlea (durum wheat) cultivar was used as an out group marker.

\section{DNA extraction and PCR amplification}

Samples were ground in a mortar to a fine powder and DNA was extracted from five dry seeds of each accession by the modified Dellaporta method (Dellaporta et al. 1983). DNA concentration and quality was assessed by gel electrophoresis in $0.8 \%$ agarose gels prepared and run with $1 \mathrm{X}$ TAE buffer.

Amplification was performed in $30 \mu \mathrm{l}$ volumes using a PxE (ThermoHybaid) Thermocycler. Each reaction consisted of 1X Taq PCR buffer, 1 unit of Taq DNA polymerase, $0.2 \mathrm{mM}$ of each deoxyribonucleotide, $0.25 \mu \mathrm{M}$ of each primer and 20 ng of genomic DNA. The amplification protocol consisted of an initial $4 \mathrm{~min}$ denaturation step at $94^{\circ} \mathrm{C}$, followed by 30 cycles of denaturation at $94^{\circ} \mathrm{C}$ for $1 \mathrm{~min}$, annealing for $1 \mathrm{~min}$ at $65^{\circ} \mathrm{C}$ and extension at $72^{\circ} \mathrm{C}$ for $2 \mathrm{~min}$. A final extension step was performed at $72^{\circ} \mathrm{C}$ for $5 \mathrm{~min}$. The oligonucleotides used as primers were synthesized on the basis of published PCR primers designed to Dgas44 DNA sequence (Bryan et al. 1998), with the following sequences: $\mathrm{N}$, 5, CTTCTGACGGGTCAGGGGCAC 3'; P, 5' CTGAATGCCCCTGCGGCTTA AG 3'. Once amplified the samples were analyzed by electrophoresis in $1.2 \%$ agarose gels and visualised by ethidium bromide staining.

\section{Results and Discussion}

The analysis of DNA extracted from five seeds from 52 Madeiran and 72 Canarian wheat accessions allowed us to distinguish durum wheat from hexaploid accessions (Tables 1 and 2). An earlier evaluation of the Madeira wheat diversity using morphological and cytological criteria resulted in the recognition of 2 Triticum species (dos Santos and Pinheiro de Carvalho 2006) and the classification of accessions among these species. However, some doubts arose in the dis- 
tinction of T. aestivum from T. turgidum in several accessions, which results for morphological traits that could be interpreted as durum or bread wheat. These problems persisted even after caryotype analysis. This situation prompted us to find a rapid and reliable PCR-based solution to screen and distinguish between durum and bread wheat accessions. The proposed method is based on the amplification of the sequence Dgas44, which demonstrated to be an effective tool for detection of the $\mathrm{D}$ genome in wheat samples acting as a specific marker for bread wheat identification. Bryan et al. (1998) applied this sequence to a large number of wheat cultivars and demonstrated that it has a wide applicability in the identification of $\mathrm{D}$ genome in wheat. Dgas 44 is a repetitive sequence that exists in a high copy number (200-300) within the D genome of bread wheat (McNeil et al. 1994). This marker has been shown to be effective in the detection of adulteration among bread wheat flour (Bryan et al. 1998, Alary et al. 2002). Tilley (2004) used Dgas44 in the amplification of wheat sequences from DNA extracted during milling and baking. Other authors have also used this marker to analyse the composition of genome of Triticale (Tams et al. 2004).

In the present work, the amplification of Dgas 44 target sequence resulted in a band of the expected molecular size of 286 bp (Fig. 1). All DNA samples extracted from the previously identified Madeiran T. turgidum accessions failed to produce the noticeable band of the $\mathrm{D}$ genome, including the Avonlea marker, whereas DNA from $T$. aestivum cultivars produced a distinctive amplification product.

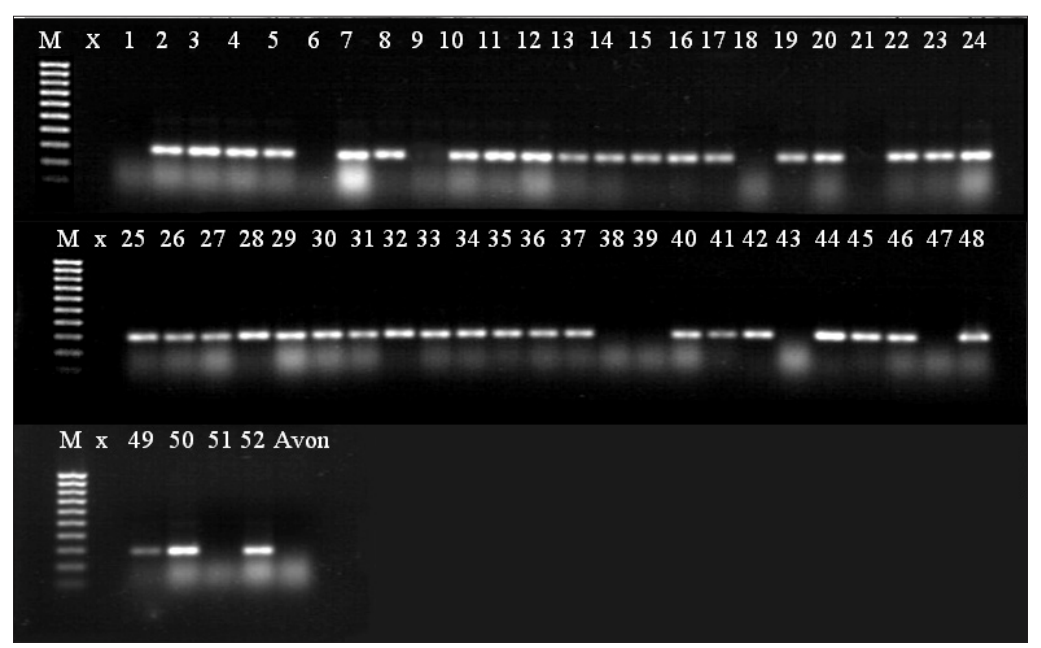

Figure 1. Agarose gel electrophoresis of PCR products generated after amplification of Dgas 44 on 52 accessions of wheat. (M) - Marker in base pairs (100 bp), (1-52) 52 accessions of wheat, (Avon) - Avonlea used as a marker 
The Dgas44 sequence was demonstrated to be effective to characterize the absence or presence of D genome in all studied accessions. Ten accessions have been identified as durum cultivars (accessions 1, 6, 9, 18, 21, 38, 39, 43, 47 and 51), corresponding to $19.2 \%$ of screened collection (Table 1 and Fig. 1). This approach allowed us to achieve $100 \%$ cases confirmation of the previous morphological and cytological classification. This method also proved to be efficient in the detection of seed mixtures and contamination as we managed to detect contamination in one of the examined accessions (\# 9). It presumed to be durum wheat, while molecular analysis revealed in the sample presence of genetic material originated from the hexaploid wheat. This particular accession has been collected in situ again to verify its ploidy status. The newly collected sample has been proven to be durum wheat. This incident instantly validated the suitability of the test for verification of seed contamination in our gene banks.

Table 1. Identification of Madeiran wheat germplasm based on morphological and molecular characterization

\begin{tabular}{|c|c|c|c|c|c|}
\hline $\begin{array}{l}\text { Sample } \\
\text { number }\end{array}$ & $\begin{array}{c}\text { Accredited } \\
\text { wheat species }\end{array}$ & $\begin{array}{l}\text { Amplification } \\
\text { results }\end{array}$ & $\begin{array}{l}\text { Sample } \\
\text { number }\end{array}$ & $\begin{array}{c}\text { Accredited } \\
\text { wheat species }\end{array}$ & $\begin{array}{l}\text { Amplification } \\
\text { results }\end{array}$ \\
\hline 1 & T. turgidum & - & 27 & T. aestivum & + \\
\hline 2 & T. aestivum & + & 28 & T. aestivum & + \\
\hline 3 & T. aestivum & + & 29 & T. aestivum & + \\
\hline 4 & T. aestivum & + & 30 & T. aestivum & + \\
\hline 5 & T. aestivum & + & 31 & T. aestivum & + \\
\hline 6 & T. turgidum & - & 32 & T. aestivum & + \\
\hline 7 & T. aestivum & + & 33 & T. aestivum & + \\
\hline 8 & T. aestivum & + & 34 & T. aestivum & + \\
\hline 9 & T. turgidum & - & 35 & T. aestivum & + \\
\hline 10 & T. aestivum & + & 36 & T. aestivum & + \\
\hline 11 & T. aestivum & + & 37 & T. aestivum & + \\
\hline 12 & T. aestivum & + & 38 & T. turgidum & - \\
\hline 13 & T. aestivum & + & 39 & T. turgidum & - \\
\hline 14 & T. aestivum & + & 40 & T. aestivum & + \\
\hline 15 & T. aestivum & + & 41 & T. aestivum & + \\
\hline 16 & T. aestivum & + & 42 & T. aestivum & + \\
\hline 17 & T. aestivum & + & 43 & T. turgidum & - \\
\hline 18 & T. turgidum & - & 44 & T. aestivum & + \\
\hline 19 & T. aestivum & + & 45 & T. aestivum & + \\
\hline 20 & T. aestivum & + & 46 & T. aestivum & + \\
\hline 21 & T. turgidum & - & 47 & T. turgidum & - \\
\hline 22 & T. aestivum & + & 48 & T. aestivum & + \\
\hline 23 & T. aestivum & + & 49 & T. aestivum & + \\
\hline 24 & T. aestivum & + & 50 & T. aestivum & + \\
\hline 25 & T. aestivum & + & 51 & T. turgidum & - \\
\hline 26 & T. aestivum & + & 52 & T. aestivum & + \\
\hline
\end{tabular}

- Absence of band; + Presence of band 
This approach was also applied to screen 72 not previously classified wheat accessions from the Canary Islands (Table 2). The collected samples were subjected to the Dgas 44 marker screening followed by the morphological and cytological characterization. We were able to rapidly identify 11 durum wheat cultivars in the 72 studied accessions, corresponding to $15.3 \%$ of the screened collection (data not shown). A large quantity of time consuming tasks needed for full

Table 2. Identification of Canarian wheat germplasm based on molecular characterization

\begin{tabular}{|c|c|c|c|c|c|}
\hline $\begin{array}{l}\text { Sample } \\
\text { number }\end{array}$ & $\begin{array}{l}\text { Amplification } \\
\text { results }\end{array}$ & $\begin{array}{c}\text { Supposed } \\
\text { wheat species }\end{array}$ & $\begin{array}{l}\text { Sample } \\
\text { number }\end{array}$ & $\begin{array}{l}\text { Amplification } \\
\text { results }\end{array}$ & $\begin{array}{c}\text { Supposed } \\
\text { wheat species }\end{array}$ \\
\hline 1 & + & T. aestivum & 37 & + & T. aestivum \\
\hline 2 & + & T. aestivum & 38 & + & T. aestivum \\
\hline 3 & + & T. aestivum & 39 & + & T. aestivum \\
\hline 4 & + & T. aestivum & 40 & + & T. aestivum \\
\hline 5 & + & T. aestivum & 41 & + & T. aestivum \\
\hline 6 & - & T. turgidum & 42 & + & T. aestivum \\
\hline 7 & - & T. turgidum & 43 & + & T. aestivum \\
\hline 8 & + & T. aestivum & 44 & + & T. aestivum \\
\hline 9 & + & T. aestivum & 45 & + & T. aestivum \\
\hline 10 & + & T. aestivum & 46 & + & T. aestivum \\
\hline 11 & + & T. aestivum & 47 & - & T. turgidum \\
\hline 12 & + & T. aestivum & 48 & - & T. turgidum \\
\hline 13 & + & T. aestivum & 49 & - & T. turgidum \\
\hline 14 & + & T. aestivum & 50 & - & T. turgidum \\
\hline 15 & + & T. aestivum & 51 & - & T. turgidum \\
\hline 16 & + & T. aestivum & 52 & + & T. aestivum \\
\hline 17 & + & T. aestivum & 53 & - & T. turgidum \\
\hline 18 & + & T. aestivum & 54 & + & T. aestivum \\
\hline 19 & - & T. turgidum & 55 & + & T. aestivum \\
\hline 20 & - & T. turgidum & 56 & + & T. aestivum \\
\hline 21 & + & T. aestivum & 57 & + & T. aestivum \\
\hline 22 & + & T. aestivum & 58 & + & T. aestivum \\
\hline 23 & + & T. aestivum & 59 & + & T. aestivum \\
\hline 24 & + & T. aestivum & 60 & + & T. aestivum \\
\hline 25 & + & T. aestivum & 61 & + & T. aestivum \\
\hline 26 & - & T. turgidum & 62 & + & T. aestivum \\
\hline 27 & + & T. aestivum & 63 & + & T. aestivum \\
\hline 28 & + & T. aestivum & 64 & + & T. aestivum \\
\hline 29 & + & T. aestivum & 65 & + & T. aestivum \\
\hline 30 & + & T. aestivum & 66 & + & T. aestivum \\
\hline 31 & + & T. aestivum & 67 & + & T. aestivum \\
\hline 32 & + & T. aestivum & 68 & + & T. aestivum \\
\hline 33 & + & T. aestivum & 69 & + & T. aestivum \\
\hline 34 & + & T. aestivum & 70 & + & T. aestivum \\
\hline 35 & + & T. aestivum & 71 & + & T. aestivum \\
\hline 36 & + & T. aestivum & 72 & + & T. aestivum \\
\hline
\end{tabular}

- Absence of band; + Presence of band 
characterization of the accessions was avoided, and thus improved the management and quality control of the germplasm collection. This approach can also be used for a first verification of seed contamination in gene bank sample management and can be important for industry and flour analysis.

Although we are convinced that we have successfully identified the durum accessions among the Madeiran and Canarian wheat germplasm based on morphological evidences, the existence of false negatives selected by the use of Dgas 44 marker cannot be entirely excluded. To avoid a remote possibility of misidentification and to assure unconditional reliability of this test the Dgas44 negative accessions need to be further screened with a second molecular marker specific for high molecular weight glutenins (HMWGs) for example the primers allele- specific for identification of $D y 10$ or $D y 12$ (Ahmad 2000). Durum accessions exhibit the lack of these subunits and it would be the ultimate proof of the nature of these accessions.

However, one has to remember that full and comprehensive accessions studies, including a complete morphological, biochemical and molecular characterization need to be made in order to obtain passport data and complete variety characterization.

This work has contributed to the knowledge of the agricultural heritage of the Madeira and Canary archipelagos, specifically to the wheat diversity in the framework of a long germplasm monitoring and characterization study of the cultivated wheat varieties of the Archipelago of Madeira and Macaronesian Region.

\section{Acknowledgements}

The authors are grateful to the Portuguese Foundation for the Science and Technology (FCT), European Union (UE) for financial support, through the projects POCI 56188/AGR/2004 and INTERREG-IIIB. 03/MAC/4.1/C15.

\section{References}

Alary, R., Serin, A., Duviau, M.P., Joudrier, P., Gautier, M.F. 2002. Quantification of common wheat adulteration of durum wheat pasta using real-time quantitative polymerase chain reaction (PCR). Cereal Chem. 79:553-558.

Ahmad, M. 2000. Molecular marker-assisted selection of HMW glutenin alleles related to wheat bread quality by PCR-generated DNA markers. Theor. Appl. Genet. 101:892-896.

Bryan, G.J., Dixon, A., Gale, M.D., Wiseman, G. 1998. A PCR based method for the detection of hexaploide wheat adulteration of durum wheat and pasta. J. Cereal Sci. 28:135-145.

Dellaporta, S.L., Word, J., Hicks, J.B. 1983. A plant DNA minipreparation: Version II. Plant Molecular Biology Report 1:19-22. 
Dograr, N., Akin-Yalin, S., Akkaya, M.S. 2000. Discriminating durum wheat cultivars using highly polymorphic simple sequence repeat DNA markers. Plant Breed. 119:360-362.

Dos Santos, T.M.M., Pinheiro de Carvalho, M.A.A. 2006. Trigos da Macaronésia. Diversidade dos Trigos Regionais do Arquipélago da Madeira. Germobanco, Funchal, 122 pp.

Manifesto, M.M., Schlatter, A.R., Hopp, H.E., Suárez, E.Y., Dubcovsky, J. 2001. Quantitative Evaluation of genetic diversity in wheat germplasm using molecular markers. Crop Sci. 41:682-690.

McNeil, D., Lagudah, E.S., Hohmann, U., Appels, R. 1994. Amplification of DNA sequences in wheat and its relatives: the Dgas44 and R350 families of repetitive sequences. Genome 37:320-327.

Pasqualone, A., Lotti, C., Blanco, A. 1999. Identification of durum wheat cultivars and monovarietal semolinas by analysis of DNA microsatellites. Eur. Food Res. Technol. 210:144-147.

Perry, D.J. 2004. Identification of Canadian durum wheat varieties using a single PCR. Theor. Appl. Genet. 109:55-61.

Pinheiro de Carvalho, M.A.A., Slaski, J.J., Dos Santos, T.M.M., Ganança, F.T., Abreu, I., Taylor, G.J., Clemente Vieira, M.R., Popova, T.N., Franco, E. 2003. Identification of aluminium tolerant genotypes among Madeiran regional wheats. Communications in Soil Sciences and Plant Analysis 34(19-20):2973-2985.

Tams, S.H., Bauer, E., Oettler, G., Melchinger, A.E. 2004. Genetic diversity in European winter triticale determined with SSR markers and coancestry coefficient. Theor. Appl. Genet. 108:1385-1391.

Tilley, M. 2004. PCR amplification of wheat sequences from DNA extracted during milling and baking. Cereal Chem. 81:553-558.

Vieira, A. 1983. O Comércio de cereais dos Açores para a Madeira no século XVII. Boletim do Instituto Histórico da Ilha Terceira. 16:651-677. 